\title{
UMA ANÁLISE SOBRE COMPLIANCE E A EDUCAÇÃO EM DIREITOS HUMANOS PARA A DESJUDICIALIZAÇÃO NO BRASIL CONTEMPORÂNEO
}

\author{
Thiago Allisson Cardoso de Jesus* \\ Rosélia Araújo Rodrigues dos Santos**
}

\section{RESUMO}

Compliance e a educação em direitos humanos para a desjudicialização no Brasil. Discute abertura da pauta para estratégias para gerenciamento de riscos, com destaque ao Compliance como instrumento hábil para afirmação da cultura de direitos humanos, voltadas a preservar e assegurar direitos. Analisa preceitos convencionais que sustentam a educação em direitos humanos e os mecanismos de Compliance no plano internacional e reflete sobre os entraves. Por meio de pesquisa empírica, discute as percepções e as fragilidades do ensino superior na seara, considerando o contexto brasileiro. Fez uso de técnicas de pesquisa bibliográfica, documental, análise de conteúdo e de discurso.

Palavras-chave: Compliance. Direitos. Proteção. Entraves. Percepções.

\section{ANALYSIS ABOUT COMPLIANCE AND HUMAN RIGHTS EDUCATION FOR DEJUDICIALIZATION IN CONTEMPORARY BRAZIL}

\begin{abstract}
Compliance and human rights education for dejudicialization in Brazil. Discusses the opening of the agenda for the new strategies for risk management, as Compliance as a skillful instrument for affirming the culture of human rights, aimed at preserving and ensuring the protection of rights. Analyzes the various conventional precepts that support human rights education and Compliance mechanisms at the international level and reflects on the obstacles. Through empirical research, it discusses the perceptions and weaknesses of higher education in the field, considering the Brazilian context. Used of bibliographic, documentary, content analysis and discourse techniques.
\end{abstract}

Keywords: Compliance. Rights. Protection. Obstacles. Perceptions.

\section{INTRODUÇÃO}

\footnotetext{
* Advogado. Doutor e Mestre em Políticas Públicas pela Universidade Federal do Maranhão. Especialista em Compliance pelo Universidade de Coimbra. Pós-Doutor em Ciências Criminais pela Pontifícia Universidade Católica do Rio Grande do Sul; e em Desigualdades Globais e Justiça Social (Capes/Print) pela Faculdade de Direito da Universidade de Brasília (UnB) e pela Faculdade Latinoamericana de Ciências Sociais (FLACSo). Professor Permanente do Mestrado Profissional em Direito da Universidade Ceuma. Professor Adjunto I no Curso de Direito da Universidade Estadual do Maranhão e na Universidade Ceuma. Orientador de Iniciação Científica (FAPEMA e CNPQ). Líder do NEPPC/UEMA/DGP-Capes e NEESS/CEUMA/DGP-Capes. Endereço eletrônico: t_allisson@hotmail.com

** Advogada. Mestranda em Direito e Afirmação de Vulneráveis na Universidade Ceuma. Especialista em Direito do Estado. Professora e pesquisadora no Núcleo de Estudos em Estado, Segurança Pública e Sociedade/ NEESS/CEUMA/DGP-Capes. Endereço eletrônico: estudoseprojetos2018@ yahoo.com
} 
O movimento pela afirmação dos direitos humanos perpassa a compreensão de uma história de aniquilamentos e indiferença às diversas violações. Nesse sentido, urge a abertura da pauta para novas estratégias que fomentem o reconhecimento de direitos e, também, a percepção das diversas condutas potencialmente violadoras desses direitos, nesses tempos de instabilidade, de fortalecimento do Estado Penal e dos paradigmas que enaltecem o punitivismo, as mentalidades inquisitórias e as políticas de enfrentamento, notadamente reativas e repressivas.

Contextualmente situado, o Brasil reflete suas escolhas político-criminais a partir de alarmante sintomatologia: experimentamos um encarceramento em massa, com população carcerária que ultrapassou 800 mil presos segundo os Dados do Departamento Penitenciário Nacional, gerando uma altíssima taxa de aprisionamento e déficit de vagas (BRASIL, 2020a), de uma intensa judicialização nos moldes estatísticos da métrica sistematizada pelo Relatório Justiça em Números (BRASIL, 2020b) e de uma baixa credibilidade por parte da população nas instituições que compõem o Sistema de Justiça Brasileiro (FUNDAÇÃO GETÚLIO VARGAS, 2017).

Ademais, relevante marcador é o que sinaliza o tempo médio de processamento, nas diversas esferas de responsabilização e instâncias judiciárias, corroborando uma intensa, e silenciada, violação ao direito humano a uma prestação em tempo hábil, razoável e justa conforme os preceitos internacionais insculpidos na Convenção Americana de Direitos Humanos (Pacto de San José), da qual o Brasil é um dos signatários.

No contexto do que fora denominado de expansão global do Poder Judiciário, protagonismo sociopolítico do sistema judicial e do primado da judicialização da vida (SANTOS, 2010), emerge a necessidade da configuração de novas estratégias políticas de acesso a justiça e afirmação de direitos, sem necessária intervenção desse poder constituído, compreendendo, inclusive, isso como uma repercussão positiva de uma efetiva educação em direitos humanos, de resguardo e proteção aos direitos humanos declarados, afirmados prima facie e sem prescindir do movimento do Sistema de Justiça.

É nesse sentido que se situa o presente contributo a literatura especializada, contextualmente situada na sociedade do risco, para a discussão em torno do Compliance no presente artigo usa-se como marco teórico as lições de Beck (2006), consoante a qual as consequências da modernização poderão ser percebidas em momentos distintos, a partir do que Silva Sanchez (2001, p. 27) presumiu que a sociedade atual é marcada por "um marco 
econômico rapidamente cambiante e pela aparição de avanços tecnológicos incomparáveis em toda a história da humanidade".

Dialogando com Beck (2006), Giddens (1991, p. 33) relembra que a palavra risco vem "provavelmente de um termo náutico espanhol que significa correr para o perigo ou ir contra uma rocha". Albuquerque (2018, p. 29) lecionou que "o risco refere-se de forma primária à noção de perigo, vez que não se pode falar em risco sem potência ou iminência de perigo". Na mesma senda epistemológica, vale frisar as lições de Bottini (2013, p. 24) que preconizou que "a definição objetiva do perigo como uma situação de fato permite caracterizar o risco como a qualidade de uma situação que a antecede".

Com Beck (2006, p. 333), corrobora-se que "risks pressupose human decisions". Em tradução livre, riscos pressupõem decisões humanas. Assim, pressupõe-se que "a sociedade atual caracteriza-se notoriamente como uma sociedade de riscos, no sentido de que encontrase ativamente ocupada debatendo, prevenindo e gerenciando riscos por ela mesma produzidas" (ALBUQUERQUE, 2018, p. 33).

Destarte, nesse ambiente de riscos socialmente produzidos, afigura-se o Compliance como uma relevante estratégia para a afirmação prima facie de direitos e para a desjudicialização como repercussão direta dos implementos de uma Cultura de Paz e de uma agenda comprometida com os Objetivos para o Desenvolvimento Sustentável apregoado pela Organização das Nações Unidas/Agenda 2030.

A Agenda, entre diversos objetivos estabelecidos para a concretização de um desenvolvimento sustentável, sinalizou preocupação em "promover sociedades pacíficas e inclusivas para o desenvolvimento sustentável, proporcionar o acesso a justiça para todos e construir instituições eficazes, responsáveis e inclusivas em todos os níveis" através do Objetivo 16 intitulado Paz, Justiça e Instituições Eficazes (NAÇÕES UNIDAS BRASIL, 2021, não paginado).

Por meio desse Objetivo, reitera-se a preocupação na efetivação de direitos e também na cultura de preservação de direitos a partir dos mecanismos que fomentem o cumprimento de leis; o fortalecimento da transparência e da eficácia das instituições; e a tomada de decisões responsivas, inclusivas, participativas e representativas em todos os níveis com o fito de enfrentamento da corrupção, das diversas violências e vulnerabilidades que maculam a sustentabilidade em sua acepção mais ampla (ORGANIZAÇÃO DAS NAÇÕES UNIDAS, 2017). De fato, a Agenda alude aos sistemas global e regionais de proteção aos direitos humanos e toma por base a proteção a pessoa, em suas múltiplas dimensões e distintas 
relações. Insere-se aqui, então, o debate acerca da primazia da educação em direitos humanos, reconhecendo, amparado em Mazzuoli (2020, p. 421) que "tanto as normas internacionais de proteção dos direitos humanos quanto a Constituição Federal de 1988 impõem ao Estado e ao cidadão a tarefa de educar (dever) e ser educado (direito) em direitos humanos e cidadania". Inclusive, a educação em direitos humanos é um dos eixos orientadores do $3^{\circ}$ Programa Nacional de Direitos Humanos, cujas diretrizes constantes no artigo $2^{\circ}$ tem por finalidades (BRASIL, 2010, p. 7), entre outras, “efetivar os princípios da política nacional de educação em direitos humanos para fortalecer uma cultura de direitos".

Nesse cenário, elegeu-se como problema de pesquisa para o presente artigo: quais são as relações do Compliance com a efetivação da educação em Direitos Humanos e em que consistem os limites e entraves para sua implementação nesse contexto de busca de novas estratégias pela desjudicialização e afirmação de direitos no Brasil Contemporâneo?

A hipótese central é que a intensa judicialização experimentada no Brasil tem fundamento no descompromisso convencional com as diretrizes internacionais que versam sobre proteção e preservação dos direitos humanos, no desconhecimento e não-aplicação das normas de soft law pertinentes a questão e no silêncio das matrizes curriculares voltadas ao percurso formativo traçados para o Ensino Superior no que toca aos conteúdos pertinentes sobre Compliance, voltados a formação integral de um profissional para atuar efetivamente no gerenciamento de crises a fim de consolidar a cultura de direitos humanos e a atuação do Sistema de Justiça Criminal como ultima ratio.

Para tanto, a pesquisa possui natureza exploratória, faz abordagem qualitativa e quantitativa dos dados e usa técnicas de pesquisa bibliográfica, documental, análise de conteúdo e de discurso. Aplicou questionários, em meio a pandemia, com o uso do software Microsoft Forms, a uma amostra de 69 pessoas, entre homens e mulheres, graduandos e já formados nas diversas áreas em instituições públicas e privadas de ensino superior. O intento dessa diversidade foi subsidiar a análise acerca das percepções sobre o Compliance, bem como de seu (des)conhecimento como estratégia relevante para a afirmação de direitos a partir da necessária desjudicialização.

O plano de investigação compreenderá duas seções. A primeira volta-se, a partir de um exercício de síntese profunda, a sistematização de fundamentos e marcos teóricos pertinentes para a compreensão da relação entre Compliance, educação em Direitos Humanos e o vetor da prevenção no resguardo de direitos como estratégias consolidadas para a efetivação da desjudicialização. A segunda, em uma imersão crítica e por meio de uma 
pesquisa empírica, analisará os entraves, discutindo possibilidades e perspectivas, a partir de referenciais teórico-políticos pertinentes e da percepção sistematizada a partir dos questionários aplicados.

\title{
2 EDUCAÇÃO EM DIREITOS HUMANOS A PARTIR DO COMPLIANCE E A CONSTRUÇÃO DE UMA CULTURA DE DESJUdiCIALIZAÇÃO PARA O BRASIL
}

Para uma escorreita compreensão dos diversos fundamentos que sustentam a educação em direitos humanos como necessidade para a contemporaneidade, vislumbra-se, como oportuno, revelar algumas premissas necessárias para afirmação da investigação que aqui pretende ser feita.

Amparando-nos em Santos (2010), parte-se do entendimento que versar sobre Compliance é também colocar em xeque os padrões conservadores e (im)postos historicamente e que aniquilam qualquer outra estratégia que tende a ser denominada, por um viés reducionista, como alternativa.

Denominar-se-á aqui, então, de estratégia, para bem fincar fundamentos e motivos para seu uso, para além da predominância ou não de sua utilização. Por isso, como ponto de partida para a discussão sistematiza-se algumas premissas para problematizar o senso comum jurídico atual. Nessa linha,

\begin{abstract}
A primeira é uma crítica ao monopólio estatal e científico do Direito. Esta premissa exige que sejam desveladas as alternativas ao dogmatismo jurídico e à teoria positivista do direito apostando numa concepção forte de pluralismo jurídico e numa concepção política do direito. [...] A segunda premissa consiste no questionamento do caráter despolitizado do direito e sua necessária repolitização. A posição eminentemente política do liberalismo de reduzir o Direito ao Estado foi a primeira condição da despolitização do Direito. A crítica desta posição leva a reconfigurar o papel da primeira instância de resolução de conflitos e aplicação do Direito erigida nos marcos da modernidade, os tribunais. [...] A terceira premissa do novo senso comum jurídico requer que se amplie a compreensão do direito como princípio e instrumento universal da transformação social politicamente legitimada, dando atenção para o que tenho vindo designar legalidade cosmopolita ou subalterna. [...] $\mathrm{O}$ pensamento jurídico insurgente e de oposição aqui proposto reivindica a reinvenção do reformismo como jargão da prática política da justiça. (SANTOS, 2010, p. 14-15).
\end{abstract}

Configura-se, aqui, profícuo debate sobre as funções do Poder Judiciário ante a intensa zona de conflituosidade, que é inerente a convivência em sociedade; a marginalização de algumas estratégias para o trato e gerenciamento das crises, considerando a sociologia das emergências e das ausências que sinaliza as prioridades e revela as pautas obscurecidas na formação profissional no campo do Direito, repercutindo na formação predominantemente tecnicista e reativa das diversas carreiras jurídicas a legitimar o protagonismo do Poder 
Judiciário como expressão estatal predominante no gerenciamento de conflitos; a constitucionalização de diversos direitos que restaram dependentes de políticas públicas para sua efetivação atraindo, por via de consequência, a atuação em primazia do Judiciário; e sobre tantas outras faces, das múltiplas relações, que fazem desse ambiente um locus de distintas tensões e contradições (SANTOS, 2010).

Nesse cenário complexo, a educação em direitos humanos possui relevante importância. Como expressão das necessidades reveladas em preceitos convencionais diversos, traduzem a preocupação na formação de novos sujeitos, protagonistas de um tempo de desencantos e de muitos entraves na afirmação e concretização de direitos. Trata-se de responsabilidade atribuída a todas as pessoas, físicas e jurídicas, estatais ou não; e volta-se para a consolidação da própria cidadania no país. Sua ausência "destrói, pois, todo o referencial ético e principiológico conquistado ao longo desses vários anos, desde antes a proclamação da Declaração Universal de 1948, não obstante o alto preço pago por toda a sociedade internacional para a consagração desses direitos". (MAZZUOLI, 2020, p. 424).

Decerto, a educação em direitos humanos possui diversos marcos normativos, no plano interno e externo. No que toca a arena internacional, a Declaração Universal de Direitos e Deveres do Homem, de 1948 apregoou que a educação em direitos humanos deve ser "orientada no sentido do pleno desenvolvimento da personalidade humana e do fortalecimento e do respeito pelos direitos humanos e pelas liberdades fundamentais", demarcando postulados de uma cultura de resguardo e proteção aos direitos já declarados (ORGANIZAÇÃO DOS ESTADOS AMERICANOS, 1948, não paginado).

A Resolução 59/113 da Assembleia Geral da ONU enunciou que "a educação na esfera dos direitos humanos é um processo a longo prazo que se prolonga durante toda a vida, no qual todas as pessoas aprendem a ser tolerantes, a respeitar a dignidade dos demais e os meios e arbítrios de assegurar esse respeito em todas as sociedades" (ORGANIZAÇÃO DAS NAÇÕES UNIDAS, 2006, p. 40), o que realça o aspecto formativo, integral e holístico para gerar novos indivíduos, engajados e comprometidos com a efetivação de direitos.

Já a Declaração das Nações Unidas sobre Educação e Formação em matéria de direitos humanos reconheceu que "[...] são essenciais para a promoção do respeito universal e efetivo de todos os direitos humanos e as liberdades fundamentais de todas as pessoas, de conformidade com os princípios da universalidade, indivisibilidade e interdependência" (ORGANIZAÇÃO DAS NAÇÕES UNIDAS, 2006, p. 2). 
Com efeito, é salutar concluir que esses e tantos outros marcos aplicáveis reforçam a ideia de que a cultura de direitos humanos perpassa a cultura de proteção e preservação desse grande mosaico de acervo de direitos inerentes a condição de pessoa humana. O Compliance se insere nesse fio condutor da preservação do acervo de direitos da pessoa humana.

A face preventiva e as práticas de monitoramento para verificação das conformidades das condutas perpetradas estão intrinsecamente comprometidas com a afirmação de direitos. O gerenciamento de riscos para que, descontrolados, não eclodam em situação de violências ou práticas de corrupção (SAAD-DINIZ; SILVEIRA, 2015) constituem necessários avanços de processo civilizatório e dos diversos sistemas de proteção de direitos humanos. Justifica-se aqui a governança corporativa, de riscos e incertezas (RODRIGUES, 2019, p. 47),

O Compliance, nesse cenário de governança corporativa, não se resumiria a um programa, mas um movimento cheio de perspectivas e desafios. A exemplo da relevância internacional dos mecanismos de Compliance, destaque às diretrizes aprovadas em 2011 pelo Conselho de Direitos Humanos da ONU e que versam sobre os Princípios Orientadores sobre Empresas e Direitos Humanos.

$\mathrm{O}$ intento dos 31 princípios ali insculpidos seria "tentar impedir que empresas violem direitos humanos no curso de suas atividades e exigir a reparação devida quando as infrações a tais direitos se perpetrarem no contexto empresarial.” (MAZZUOLI, 2020, p. 438, grifo nosso). Exemplificando, pois: um programa chamado Proteger, Respeitar e Reparar foi apresentado como um norte para a promoção e proteção dos direitos humanos nas atividades desenvolvidas pelos Estados e pelas empresas. In verbis, alguns de seus salutares enunciados (BRASIL, 2019, p. 12-17, grifo nosso):

I. O dever do Estado de proteger os direitos humanos Princípio 1

Os Estados devem proteger contra violações dos direitos humanos cometidas em seu território e/ou sua jurisdição por terceiros, inclusive empresas. Para tanto, devem adotar as medidas apropriadas para prevenir, investigar, punir e reparar tais abusos por meio de políticas adequadas, legislação, regulação e submissão à justiça

Princípio 2

Os Estados devem estabelecer claramente a expectativa de que todas as empresas domiciliadas em seu território e/ou jurisdição respeitem os direitos humanos em todas suas operações.

Princípio 3

A. Fazer cumprir as leis que tenham por objeto ou por efeito fazer as empresas respeitarem os direitos humanos, avaliar periodicamente se tais leis resultam adequadas e remediar eventuais lacunas; 
B. Assegurar que outras leis e diretrizes políticas que regem a criação e as atividades das empresas, como o direito empresarial, não restrinjam mas sim que propiciem o respeito aos direitos humanos pelas empresas;

C. Assessorar de maneira eficaz as empresas sobre como respeitar os direitos humanos em suas atividades;

D. Estimular e se for preciso exigir que as empresas informem como lidam com o impacto de suas atividades sobre os direitos humanos.

$[\ldots]$

Princípio 7

Tendo em vista que o risco de graves violações de direitos humanos é maior em regiões afetadas por conflitos, os Estados devem tratar de assegurar que as empresas que operem em tais contextos não se vejam implicadas em abusos dessa natureza, adotando entre outras as seguintes medidas:

A. Colaborar o mais cedo possível com as empresas para ajudá-las a identificar, prevenir e mitigar os riscos para os direitos humanos que impliquem suas atividades e relações empresariais;

B. Prestar assistência adequada às empresas para avaliar e tratar os principais riscos de abusos, prestando especial atenção tanto à violência de gênero quanto à violência sexual;

C. Negar o acesso ao apoio e serviços públicos a toda empresa que esteja envolvida em graves violações dos direitos humanos e se negue a cooperar para resolver a situação;

D. Assegurar a eficácia das políticas, leis, regulamentos e medidas coercitivas vigentes para prevenir o risco de que as empresas se vejam envolvidas em graves violações dos direitos humanos.

Não obstante afigurarem-se como normas de soft law (SARMIENTO, 2008), os diversos preceitos internacionais protetivos de direitos humanos, com alcance global ou regional, constituem mecanismos hábeis para a verificação de conformidades e eventuais descompassos de regularidade via implementação de sistemas de Compliance, integrados por equipes multiprofissionais. De fato, como afirma Mazzuoli (2020, p. 452, grifo nosso), “[...]sua efetividade advém do respeito que todas as corporações devem ter às normas domésticas e também às normas internacionais (de hard law ou soft law, sobretudo em matéria de direitos humanos) de que o Estado em que se operam faz parte."

Etimologicamente, o termo Compliance denota atuação em conformidade, em acordo com padrões previamente estabelecidos.

Caracterizando-se como razoável e esperado de toda instituição, a estratégia de Compliance confronta-se com a ambiência de intensa judicialização, violação de direitos e primazia do Poder Judiciário para a efetivação de direitos, na condição de poder estatal constituído a atuar na finalidade reparadora de direitos, por meio de responsabilizações diversas. Apresenta-se o Compliance como uma estratégia antiga, em que pese a inexistência de um marco histórico e de um processo codificador como o que ocorre na lógica técnicajurídica positivista hegemônica que tem guarida no extenso numerário de normas legais que 
compõe os ordenamentos jurídicos hodiernos, inclusive o brasileiro. Nieto Martín (2015, p. 27) rememora que

\begin{abstract}
Nos países cuja base legislativa é proveniente do civil law, o surgimento e posterior consolidação do cumprimento normativo deu-se de forma tardia, sendo proveniente justamente de um processo de americanização dos seus ordenamentos jurídicos, em que diversos institutos criados no âmbito do common law americano passam a ser inseridos nas legislações nacionais destes estados. Apenas em tempos recentes, portanto, o Compliance vem alcançando um patamar global de influência.
\end{abstract}

Para Albuquerque (2018), alguns regramentos, de origem estadunidense, foram progressivamente constituindo o corpus estruturante dos diversos programas de Compliance, a exemplo da Foreign Corrupt Practices Act (1977), Sarbanes-Oxley Act (2002), Dodd-Frank Act (2010); e que a introdução nas práticas das empresas e amparo nos Ordenamentos Jurídicos gera movimento de reflexividade, pois influencia e é influenciada pelos fenômenos da a) autorregulação regulada, compreendendo a interação entre as medidas autorregulatórias próprias das empresas e a regulação feita pelo aparato estatal; b) a governança corporativa, considerando os impactos interna e externamente, geradas pelas decisões tomadas pela empresa, abarcando os processos, os sistemas e controles organizacionais utilizadas pela empresa; c) a responsabilidade social da empresa, que busca um equilíbrio entre a atuação da empresa e os interesses afetados, inclusive negativamente, pela atividade empresarial desenvolvida, fitando atenuar ou minimizar impactos nefastos; d) e a ética empresarial, almejando a good corporate citizen, a fim de consolidar valores e princípios éticos (ALBUQUERQUE, 2018; GARCIA CAVEIRO, 2014; LEEÓN BERINI, 2013; MILLER, 2014; NIETO MARTÍN, 2008; TARANTINO ).

Ademais, sobre Compliance, passa-se a sistematização de algumas chaves para sua delimitação conceitual, considerando as singularidades de cada programa estabelecido e as diversas expressões desse fenômeno de múltiplas faces, de escassa literatura e pífia previsão normativa, notadamente para o trato no Brasil.

Para Cocavila (2013, p. 54), deve ser visto como o "conjunto efetivo de medidas direcionadas a garantir que cada um dos membros da empresa [...] cumpra com os mandados e proibições jurídicas estabelecidos em lei e que, acaso reste evidenciada uma prática infratora, seja possível o seu descobrimento e sanção".

Segundo Miller (2014), Compliance seria o processo através do qual uma organização procura assegurar que os seus empregados e demais constituintes se adequem às normativas aplicáveis dos diversos ordenamentos vigentes, oriundos do Estado, a exemplo 
das normas penais, administrativas cíveis e societárias; ou provenientes da própria empresa, como códigos de ética, políticas, códigos de conduta, etc.

Lascuraín (2013) apregoa que trata-se de um sistema de devido controle da pessoa jurídica, direcionados à obtenção da obediência a determinadas normas no exercício da atividade empresarial.

Com repercussão importante na seara criminal, ultima ratio para a tutela de bens jurídicos no Brasil, situa-se em um conflito de paradigmas, em ambiente historicamente reativo e de enfrentamento. Passa-se também a falar em monitoramento, fiscalização e regulação em matéria penal. Aduz Saad-Diniz (2019, p. 256) que

Es en esse contexto particular que la investigácion cientifica sobre las causas,
controles y estratégias de acción recobra su relevância. Por um lado, se adquiere
solidez en la individualización de los agentes, dimensiones del daño, processos de
victimización, em qué medida se puede hablar sobre efecto intimidatório
(deterrence) o preventivo, evaluación de la cualidad de las iniciativas de
enforcement, politicas regulatórias e iniciativas corporativas. Por outro, superando
la mentalidade repressiva y el apego al control social formal, discutiendo las
possibilidades de estabelecer vínculos colaborativos entre la acción del particular y
los órganos fiscalizadores y reguladores.

Afigurando-se como programa, sistema ou expressão das relações de controle e disciplina no âmbito das organizações, públicas ou privadas, na pauta encontra-se o gerenciamento de riscos em uma contemporaneidade de conflituosidade intrínseca e o necessário fortalecimento a cultura de afirmação de direitos a partir de seu viés preventivo.

Baseando-se no a) estabelecimento da cultura de cumprimento das normas estabelecidas, b) da necessária independência do setor de Compliance com relação aos demais departamentos da empresa, c) da integração com as diversas áreas de atuação da pessoa jurídica, d) da real análise, gestão e controle de riscos, e) elaboração de um código de conduta e de políticas de cumprimento, f) criação e manutenção de um Canal de Denúncias (Whistleblowing), g) Aplicação de controles de auditoria em matéria contábil e investigações internas, g) Comunicação e treinamento dos integrantes da empresa em matéria de Compliance (ALBUQUERQUE, 2018); a estruturação de um Programa de Compliance traz consigo inúmeras potencialidades e vantagens. Em matéria de afirmação de direitos humanos, é uma estratégia salutar e em conformidade com os preceitos convencionais diversos do Sistema Global de Direitos Humanos.

Frisa-se, a partir da literatura especializada, que existe uma certa padronização dos procedimentos para a análise, gestão e controle dos riscos. Albuquerque (2018, p. 114) afirma que “o processo de análise, gestão e controle de riscos é geralmente realizado seguindo as 
guidelines oferecidas por organizações internacionais. O objetivo (...) é precisamente o de uniformizar as medidas empregadas pelas corporações mediante um único procedimento universalmente reconhecido".

A face preventiva e de resguardo da educação em direitos humanos encontra-se respaldo em diversas normas internacionais, ainda que se afigurem como soft law por não implicarem em observância obrigatória e as empresas aderirem ou não, que são representativas das distintas recomendações para implementação de Sistemas de Compliance como mecanismo para preservação dos direitos humanos. Várias dessas normas, inclusive, atingem o setor privado e a atividade empresarial, per si.

Destaque para a Declaração Tripartite de Princípios sobre Empresas Multinacionais e a Política Social da Organização Internacional do Trabalho (2002), o Pacto Global da Organização das Nações Unidas (2000), as Diretrizes da OCDE para as Empresas Multinacionais (ORGANIZAÇÃO INTERNACIONAL DO TRABALHO, 2002) e os princípios orientadores sobre empresas e direitos humanos, aqui já referenciados.

No que toca às práticas dos Estados Nacionais e seus poderes constituídos, há mecanismos de Compliance vistos como instrumentais para efetivação de direitos a partir da sua proteção e preservação em diversos tratados internacionais, atingindo também as práticas da livre iniciativa.

Nessa senda, voltado ao enfrentamento da corrupção destaque a Convenção das Nações Unidas contra a Corrupção, discorrendo sobre a prevenção às práticas corruptivas e apregoando monitoramento de condutas (ORGANIZAÇÃO DAS NAÇÕES UNIDAS, 1996); para o trato da questão ambiental, seara na qual os princípios da prevenção e da precaução constituem condições sine qua non para a efetivação desse direito difuso, sublinha-se a Convenção de Basileira sobre o Controle de Movimentos Transfronteiriços de Resíduos Perigosos e seu Depósito (1989); no que toca ao crime organizado, sobreleva-se a Convenção das Nações Unidas contra o Crime Organizado Transnacional, que preconiza alinhamento para cooperação entre autoridades diversas para a escorreita aplicação da lei (ORGANIZAÇÃO DAS NAÇÕES UNIDAS, 2000).

Ademais, para o enfrentamento das vulnerabilidades e afirmação de direitos da pessoa ante o movimento que minimiza o núcleo essencial dos direitos declarados, há diversos tratados e regras oriundas do plano internacional, a exemplo dos diversos instrumentos normativos contra a discriminação, de proteção dos direitos das crianças, de proteção dos trabalhadores migrantes, das pessoas com deficiência, das comunidades 
indígenas, das pessoas em conflito com a lei penal., configurando "um mosaico protetivo que estão a exigir das empresas o Compliance na proteção dos direitos humanos, enquanto não sobrevém convenção específica da ONU sobre a questão" (MAZZUOLI, 2020, p. 452). Com efeito, como destaca o mesmo autor, "a efetividade advém do respeito que todas as corporações devem ter às normas domésticas e também às normas internacionais (de hard law ou soft law, sobretudo em matéria de direitos humanos) de que o Estado em que operam faz parte", ainda segundo o autor.

A cultura dos direitos humanos implica caminhos de prevenção, reconhecimento e reparação ante às potencialidades de violação. Fundamentando-se no gerenciamento de riscos e de busca por uma conformidade, os mecanismos de Compliance denotam uma relevante estratégia para a consolidação de um processo civilizatório comprometido com os valores da pessoa humana e com uma mentalidade que não justifique ou banalize violação a direitos em prol de um desenvolvimentismo não-engajado.

Registra-se que, no Brasil, após a edição do Decreto 9.571/2018 que fixou as Diretrizes Nacionais sobre Empresa e Direitos Humanos, um engajamento crescente de diversas empresas com os programas de proteção dos direitos humanos, ao lado da tendência mundial demonstrada pela expressiva adesão de mais de 13 mil pessoas jurídicas no Pacto Global da Organização das Nações Unidas, com atividades próprias de Compliance voltadas ao aperfeiçoamento de códigos de conduta, políticas e diretrizes empresariais, com exigência expressa de observância e nítido poder disciplinar, com amplo poder sancionatório (MAZZUOLI, 2020).

A tutela dos direitos humanos via Compliance, que reforça a preservação e a prevenção como compromissos humanitários, resguarda núcleos essenciais importante para a proteção da pessoa humana, cuja dignidade expressa a pessoa em concreto, como diria Miranda (2000).

Por meio desse gerenciamento de riscos evita-se que a pessoa humana seja submetida a condições degradantes e indecentes de trabalho e/ou às condições discriminatórias, bem como fortalece uma cultura de identificação de riscos, impactos nefastos e violação a direitos e de denúncias, reclamações e iniciativas que estejam fundadas na solidariedade social e corresponsabilidade.

\section{PERSPECTIVAS E ENTRAVES PARA A IMPLEMENTAÇÃO DO COMPLIANCE EM AMBIENTE DE NECESSÁRIA AFIRMAÇÃO DE DIREITOS HUMANOS}


Extrapolando o avanço procedimental que a implementação de Programas ou sistemas de Compliance trouxe consigo para o gerenciamento de riscos, necessário discutir suas perspectivas e entraves. Nesse contexto, parte-se da premissa utilitária de que um dos objetivos primoridiais de uma cultura preventiva de danos seria a desjudicialização, a partir da afirmação e preservação de direitos. Nessa senda, Rodrigues (2019, p. 67) frisa que "Imediatamente, os programas de compliance visam a promoção de uma cultura ética e de cumprimento, mas o seu objetivo final é evitar a responsabilidade administrativa, civil e, em última linha, mas sobretudo, penal”.

A desjudicialização afigura-se como fator para otimização da atuação do Poder Judiciário, em crise conforme "percebido por todos os seus usuários - indivíduos e empresários - e seus atores - juízes e advogados" (DAKOLIAS, 1996, p. 17) e preconizado no Documento Técnico Número 319 do Banco Mundial e intitulado O Setor Judiciário na América Latina e no Caribe: elementos para Reforma; efetiva também o acesso a justiça, em uma macrodimensão para além da estrutura orgânica do Poder Judiciário, considerando as implicações sociais e políticas da aplicação do Direito bem como as tensões entre o Direito Positivo e as sensações de injustiça e impunidade (SADEK, 2010); é necessidade ante a descrença e insatisfação do brasileiro com a administração da justiça e os problemas epistemológicos e políticos que demarcam essa era, a exemplo do legalismo formalizante, ineficácia social da aplicação das leis e o hiato entre a verdade formal e a prática social, potencializados por uma "cultura jurídica onde a justiça é apenas aquela dada pelo Estado, e não a construída pelas mãos, sentimentos e interesses das partes" (FALCÃO, 2007, p. 30). Reitera-se, com Sadek (2004, p. 79), que o atual contexto do Judiciário clama por novas práticas e que "reformas virão e mudanças já estão em curso, algumas mais e outras menos visíveis, alterando a identidade e o perfil de uma instituição que sempre teve na tradição uma garantia segura contra as inovações”.

A par disso, em uma crítica apurada, abriu-se a pauta para a discussão do Judiciário a partir do realismo jurídico que considera o tempo de sua atuação. Ou a ausência de um tempo razoável para essa atuação, implicando na banalização da impunidade e na emergência de um estado de permanente insegurança das relações sociais. Nessa linha, Araújo e Oliveira (2012, p. 528) denominou de chicana processual e castelos de fachadas as inúmeras relações nessa ambiência desastrosa empreendidas, refletindo que "as prestações insuficientes, diante da importância do papel a ele atribuído, exprimiram o despreparo do Judiciário brasileiro para responder satisfatoriamente às novas demandas sociais". 
Com efeito, em projeção, uma revolução de mentalidades. Para fins dessa análise, a formação profissional de nível superior, notadamente na área do Direito, não contemplou conteúdos direcionados a atuação no gerenciamento de riscos, denotando uma história de descompromisso com a prevenção e preservação de direitos e, ainda mais, um profundo silêncio acerca de estratégias peculiares como o Compliance.

O silêncio é notado, inclusive, nas Diretrizes Curriculares Nacionais para o Curso de Direito. Aliás, sobre os mecanismos extrajudiciais de solução de controvérsias especificamente a Mediação, a Conciliação e a Arbitragem - somente a partir de 2018 fora recomendada a inserção no currículo nos moldes das perspetivas formativas delineadas pelo Conselho Nacional de Educação (CNE) em parecer exarado com a finalidade de revisão das Diretrizes Curriculares do curso de graduação em Direito (BRASIL, 2018).

Sobre o Compliance, o silêncio é corroborado por diversas expressões e percepções. Foi nesse intento que se fez-uso da aplicação de questionários, instrumento e técnica de pesquisa hábil para análise das percepções acerca do instituto e de seu (não) conhecimento no mundo da educação superior brasileira. Foram aplicados 69 questionários, com o uso do software Microsoft Forms, entre homens e mulheres, todos acima de 18 anos, graduandos ou já formados nas diversas áreas em instituições públicas e privadas de ensino superior.

Dos questionários aplicados, foi de alta predominância a resposta positiva (SIM) quando a pergunta é "Você julga importante que os Cursos de Graduação atualizem as matrizes curriculares e insiram conteúdos novos voltados às novas práticas e tecnologias para o gerenciamento de riscos e crises?". Apenas dois dos questionados, responderam negativamente.

A necessária atualização das matrizes curriculares como resposta majoritária é corroborada, também, pelo desconhecimento acerca do Compliance. Da totalidade dos questionados, 39 responderam que não sabem do que se trata. Segundo a Taxonomia de Bloom, esse é o primeiro dos degraus do processo de conhecimento: $56 \%$ da amostra afirma desconhecimento sobre Compliance, demarcando a invisibilidade de instituto e prática tão relevante para o gerenciamento de riscos e, há tanto tempo, na pauta. Dos que responderam que saberiam conceituar o Compliance, as respostas foram distintas, destacando: "conjunto de regras, um conceito bem vago"; "o compliance seria um método de resolução de conflitos que se vale das plataformas jurídicas e dos tribunais mas dispensa a coercitividade do Direito, convidando as partes a decidirem uma saída adequada para seu conflito de maneira autônoma, independente e justa”; “é um movimento no âmbito das corporações, empresas e entidades 
que visa a conformidade da atuação delas com a legislação e princípios éticos e morais"; "adequação de uma instituição à normas do mundo corporativo", "O Compliance é o uso de instrumentos voltados para as boas práticas das normas internas e externas de uma empresa ou corporação, evitando-se judicializações desnecessárias, assim como o enfrentamento de situações de risco que maculem o nome da empresa", "Prática voltada a assegurar o cumprimento de normas (ou conjunto de normas) e comportamentos éticos dentro de determinado ambiente"; "É a criação de mecanismos a fim de que se evite questões que possam extrapolar no âmbito interno das organizações públicas ou privadas, com judicialização de demandas. É sobretudo um incentivo a cultura de combate a corrupção”. As respostas representam verdadeiro emaranhado que significa o distanciamento, paradoxal, do mundo da educação superior com o objeto da pesquisa.

A omissão nítida das Diretrizes Curriculares Nacionais acerca das estratégias para o gerenciamento de riscos - que antecedem a atuação do estado no viés da judicialização e corroborariam para o não uso da via judicial - refletem na construção das matrizes curriculares nos Cursos, bem como na estruturação dos conteúdos ministrados em cada disciplina dos diversos eixos.

Da totalidade, apenas $8,7 \%$ dos questionados afirmaram ter feito alguma disciplina que abordasse Compliance na graduação; e dos que estudaram em universidades públicas foi unanimidade a resposta que sinalizava que no âmbito da graduação as disciplinas não abarcaram nenhum conteúdo. Nas instituições privadas e públicas, a unanimidade também apontou a inexistência de uma disciplina específica para o estudo do Compliance. As respostas sobre Compliance seriam, então, oriundas de leituras, práticas e conhecimento de uma cultura geral, mas não derivam, em grande parte, do percurso formativo fomentado pelo Ensino Superior.

Decerto, sobre essa problemática, realidade empírica aqui demarcada, a consequência não seria outra: $82,6 \%$ dos questionados não se sentem preparados para o gerenciamento de riscos a partir da atuação em equipes multiprofissionais, intervenções cada vez mais presentes nas grandes corporações e expressão das novas habilidades requeridas para o bom e engajado exercício profissional nesses tempos de globalização de ideias e práticas.

Não obstante a isso, associam o Compliance a estratégias com finalidades necessárias e contextualmente situadas: em pergunta, com permissivo de múltiplas respostas, atrelaram, em ordem de prevalência, a) às práticas de monitoramento e gerenciamento de riscos; b) combate a corrupção; c) alinhamento às regras institucionais; d) enfrentamento a 
judicialização excessiva; e e) implementação de uma cultura de paz. Muitos associaram as respostas, traduzindo as finalidades múltiplas alinhadas ao Compliance, da trivial discussão sobre monitoramento, passando pelo enfrentamento da corrupção e a necessária implementação da cultura de paz e de direitos humanos (PALMA et al., 2017). Dez dos questionados, negando qualquer pré-concepção ao instituto, informaram "não sei responder".

O desconhecimento do Compliance, inclusive como instrumento de proteção e preservação de direitos atrela-se intrinsecamente ao não-reconhecimento das normas internacionais que apregoam a implementação desses salutares mecanismos de gerenciamento de riscos. Como aduz Montoro (1998, p. 22), a partir da compreensão da expressão Cultura em Direitos Humanos, "não basta ensinar direitos humanos. É preciso lutar pela sua efetividade. E, acima de tudo, trabalhar pela criação de uma cultura prática desses direitos". Um dos entraves - e consequência da globalização das formas jurídicas legais e atreladas a atuação estrita do Poder Legislativo e a dependência de uma ordem judicial emanada de um poder constituído como o Judiciário - é o revestimento jurídico de soft law de muitas normas internacionais que restam apenas por recomendar, não possuindo um caráter vinculante para obrigar ou poder de coercibilidade para aplicar sanções em caso de descumprimento.

Em que pese considerar com Mazzuoli (2020, p. 451) que "a falta de instrumento global vinculante (tratado) que discipline por completo as responsabilidades das empresas por violações a direitos humanos não autoriza as corporações a agirem com abuso de direito no âmbito de suas atividades", a ausência de obrigatoriedade e o apego ao legalismo faz com que o Brasil sofra grande impacto nessa não observância, em nível social, cultural e econômico.

A cultura de direitos humanos está às avessas e, não raro, os poderes constituídos são acionados a atuar para atuar na repressão às diversas violações de direitos, por vezes irreparáveis in natura a condição humano vulnerabilizada, a exemplo de casos de vitimização homicida e desastres ambientais, verdadeiras tragédias anunciadas.

Nesse sentido, a incorporação das práticas de Compliance na proteção e preservação de direitos assume face de direito humano fundamental: compromete-se com os postulados e diretrizes da educação em direitos humanos; fortalece a cultura de paz e de direitos humanos como objetivo para o desenvolvimento sustentável; fomenta o monitoramento de situações de riscos e situa a pessoa humana como titular e destinatária de regras de poder, ocasionado desjudicialização na medida que o Judiciário atuaria como ultima ratio; reforça os laços de fraternidade, solidariedade e esperança, pertinentes às ultimas dimensões dos direitos declarados; cria corresponsabilidade entre os diversos entes que integram essa complexa rede 
da tessitura social na afirmação, preservação e proteção dos direitos humanos, consolidando o real sentido dos estados contemporâneos que é proteger a pessoa em sua singularidade.

\section{CONSIDERAÇÕES FINAIS}

A incorporação das práticas comprometidas com o Compliance nos diversos espaços confronta-se com uma mentalidade e uma cultura de não afirmação de direitos e desresponsabilização societal no gerenciamento de crises, demarcada pelo formalismo exacerbado, pela primazia dada ao Judiciário para apreciação e solução de demandas e na fragilidade de uma cultura de direitos humanos voltada a preservação e proteção de direitos.

Ademais, falar de Compliance no Brasil revela-se desafiador, considerando o histórico percurso formativo do profissional, precisamente do Direito, que voltou-se às disciplinas de cunho técnico a fim de fomentar a atuação contenciosa das diversas carreiras jurídicas perante os poderes constituídos e não priorizou habilidades para o monitoramento de conformidades e desconformidades a partir de um assento em equipes multiprofissionais. Aliás, vale destacar a destreza do trato das disciplinas de Filosofia, Sociologia, Psicologia nos diversos cursos de Graduação pelo país, inclusive.

Além disso, necessário trazer à tona o silêncio, que muito diz, das Diretrizes Curriculares para o Curso de Direito que não contempla nos três eixos (formação fundamental, profissional e prática) conteúdos tampouco uma disciplina destinado às práticas, técnicas e experiências com o Compliance, repercutindo na forma como as novas e também as antigas gerações - que hoje estão no manejo do Sistema de Justiça- concebem e tratam essa relevante estratégia para o gerenciamento de riscos e afirmação de direitos.

Em perspectiva, a efetiva implementação do Compliance, para além de experiências isoladas, requer mudança de mentalidade na sociedade. Enraizados no punitivismo, da atuação predominantemente repressiva e reativa e na ambiência das reparações concedidas por ordens judiciais, o Brasil fez claras escolhas para o trato de sua zona de conflituosidade e algumas, como as voltadas a questão criminal, afiguram-se como alarmantes. A primazia da judicialização, aqui em excesso, retrata uma ambiência de frágil afirmação de direitos e intensa violação dos conteúdos essenciais que eles protegem.

A revolução de mentalidade perpassa, também, o reconhecimento pelo Estado das normas que apregoam sistemas de Compliance. Ainda que tenham status de soft law, constituem nítidas peças que integram o mosaico dos direitos humanos e visivelmente comprometidas com uma cultura que afirma direitos humanos e os protege, sem necessária 
violação que atraia judicialização e possível reparação, sistema retroalimentado e que faz aflorar, rotineiramente, as diversas vulnerabilidades que são intrínsecas às pessoas que nele estão, por seus dilemas, envolvidos.

A implementação do Compliance em matéria de direitos humanos almeja a efetivação prima facie, antecipando-se a violação de seus núcleos essenciais e reforçando o amplo sistema de proteção a pessoa humana. No Brasil, repercutiria positivamente fecundando a desjudicialização, na medida que realçaria a atuação preventiva de equipes multiprofissionais e impactaria na atenuação de demandas e pleitos reparatórios perante o Poder Judiciário. Ademais, a cultura do gerenciamento de riscos é salutar porque implica em menos gastos e maior satisfação com o tempo usado no trato das questões apreciadas.

Portanto, a incorporação das práticas de Compliance na proteção e preservação de direitos assume feição de direito humano fundamental, dado o compromisso com os postulados e diretrizes da educação em direitos humanos; com a cultura de paz e de direitos humanos como objetivo para o desenvolvimento sustentável; com o monitoramento de situações de riscos e situa a pessoa humana como titular e destinatária de regras de poder, provocando desjudicialização na medida que o Judiciário atuaria como ultima ratio; afigurando-se importante estratégia para o gerenciamento de crises e para fortalecer o sentido dos estados contemporâneos que é proteger a pessoa em sua singularidade.

\section{REFERÊNCIAS}

ALBUQUERQUE, Eduardo Lemos Lins de. Compliance e crime corporativo. Belo Horizonte: Editora D'Plácido, 2018.

ARAÚJO, Mayara de Carvalho; OLIVEIRA, Raisa Lustosa. Da morosidade da justiça como recurso para a manutenção do status quo: a chicana processual e os "castelos de fachadas".

Revista de Direito Brasileira, Passo Fundo, v. 4, n. 3, p. 523-543, jan./abr. 2013.

BECK, Ulrich. La sociedad del riesgo: en camino hacia otra sociedad moderna. Madrid: Paidos, 2006.

BOTTINI, Pierpaolo Cruz. Crimes de perigo abstrato. São Paulo: Revista dos Tribunais, 2001.

BRASIL. Conselho Nacional de Educação. Parecer CNE/CES nº 635, de 4 de outubro de 2018. Revisão das Diretrizes Curriculares Nacionais do curso de graduação em Direito.

Diário Oficial da União: seção 1, Brasília, DF, 17 dez. 2018. Disponível em: https://normativasconselhos.mec.gov.br/normativa/view/CNE_PAR_CNECESN6352018.pdf? query=Curr\%C3\%Adculos. Acesso em: 10 mar. 2021. 
BRASIL. Conselho Nacional de Justiça. Justiça em números 2020. Brasília, DF: Conselho Nacional de Justiça, 2020b. Disponível em: https://www.cnj.jus.br/wpcontent/uploads/2020/08/WEB-V3-Justi\%C3\% A7a-em-N\%C3\%BAmeros-2020-atualizadoem-25-08-2020.pdf. Acesso em: 10 nov. 2020.

BRASIL. Governo do Brasil. Dados sobre população carcerária do Brasil são atualizados. Brasília, DF, 17 fev. 2020a. Disponível em: https://www.gov.br/pt-br/noticias/justica-eseguranca/2020/02/dados-sobre-populacao-carceraria-do-brasil-sao-atualizados. Acesso em: 10 nov. 2020.

BRASIL. Ministério da Mulher, da Família e dos Direitos Humanos. Secretaria Nacional de Proteção Global. Princípios Orientadores sobre Empresas e Direitos Humanos:

implementando os parâmetros "proteger, repseitar e reparar" das Nações Unidas. Brasília, DF: Ministério da Mulher, da Família e dos Direitos Humanos/Secretaria Nacional de Proteção Global, 2019. Disponível em: https://www.gov.br/mdh/pt-

br/assuntos/noticias/2019/outubro/Cartilha_versoimpresso.pdf. Acesso em: 10 nov. 2020.

BRASIL. Secretaria de Direitos Humanos da Presidência da República. Programa Nacional de Direitos Humanos (PNDH-3). Brasília, DF: SDH/PR, 2010. Disponível em: https://www.ohchr.org/Documents/Issues/NHRA/ProgrammaNacionalDireitosHumanos2010. pdf. Acesso em: 20 nov. 2020.

COCAVILA, Ivó. Programas de cumplimiento como forma de autorregulación regulada. In: SILVA SÁNCHEZ, Jesús Maria. Criminalidad de empresa y compliance: prevención y reacciones corporativa. Coordenação, Raquel Montaner Fernandez. Barcelona: Atelier, 2013.

DAKOLIAS, Maria. O setor judiciário na América Latina e no Caribe: elementos para reforma. Washington: Banco Mundial, 1996. (Documento técnico, 319). Disponível em: https://forumjustica.com.br/wp-content/uploads/2014/12/WTP319-portuuguese.pdf. Acesso em: 10 nov. 2020.

FALCÃO, Joaquim. O futuro é plural: administração de justiça no Brasil. Revista USP, São Paulo, n. 74, p. 22-35, jun./ago. 2007.

FUNDAÇÃO GETÚlIO VARGAS. Escola de Direito de São Paulo. Relatório ICJ Brasil. São Paulo: Fundação Getúlio Vargas, 2017.

GARCIA CAVERO, Percy. Criminal compliance. Lima: Palestra, 2014.

GIDDENS, Anthony. Modernização reflexiva. São Paulo: UNESP, 1991.

LASCURAÍN, Juan Antonio. Compliance, debido control y unos refrescos. In: ARROYO ZAPATERO, Luis; NIETO MARTÍN, Adán . El derecho penal económico en la era compliance. Valencia: Tirant Lo Blanch, 2013.

LEEÓN BERINI, Arturo González. El criminal compliance en la reforma norteamericana de la Dodd-Frank Act. In: SILVA SÁNCHEZ, Jesús Maria; FERNANDEZ, Raquel Montaner 
(coord.). Criminalidad de empresa y compliance: prevención y reacciones corporativa. Barcelona: Atelier, 2013.

MAZZUOLI, Valério de Oliveira. Curso de direitos humanos. São Paulo: GEN, 2020.

MILLER, Geoffrey Parsons. The law of governance, risk management and compliance. Ney York: Wolters Kluwer Law y Business, 2014.

MIRANDA, Jorge. Manual de direito constitucional. Coimbra: Coimbra Editora, 2000. t. 1.

MONTORO, André Franco. Cultura dos direitos humanos. In: MARCILIO, Maria Luiza; POZZOLI, Lafayete (coord.). Cultura dos direitos humanos. São Paulo: LTR, 1998.

NAÇÕES UNIDAS BRASIL. Objetivos de Desenvolvimento Sustentável: 16 Paz, Justiça e Instituições Eficazes. Brasília, DF: Nações Unidas Brasil, 2021. Disponível em: https://brasil.un.org/pt-br/sdgs/16. Acesso em: 10 mar. 2021.

NIETO MARTÍN, Adán. El cumplimiento normativo. In: NIETO MARTINS, Adán (org.). Manual de cumplimiento penal en la empresa. Valência: Tirant Lo Blanch, 2015.

NIETO MARTIN, Adán. Responsabilidad social, gobierno corporativo y autorregulación: sus influencias em el derecho penal de la empresa. Política Criminal, [S. l.], v. 3, n. 5, p. 1.18, 2008.

ORGANIZAÇÃO DAS NAÇÕES UNIDAS. Escritório das Nações Unidas contra Drogas e Crimes. Convenção das Nações Unidas contra a Corrupção. Brasília, DF: Escritório das Nações Unidas contra Drogas e Crimes ,1996. Disponível em: https://www.unodc.org/documents/lpobrazil/Topics_corruption/Publicacoes/2007_UNCAC_Port.pdf. Acesso em: 10 nov. 2020.

ORGANIZAÇÃO DAS NAÇÕES UNIDAS. Escritório das Nações Unidas sobre Drogas e Crime. Convenção das Nações Unidas contra o Crime Organizado Transnacional. Palermo: Escritório das Nações Unidas contra Drogas e Crimes, 2000. Disponível em: https://www.unodc.org/lpo-brazil/pt/crime/marco-legal.html. Acesso em: 10 nov. 2020.

ORGANIZAÇÃO DAS NAÇÕES UNIDAS. Programa das Nações Unidas para o Desenvolvimento. Plataforma Agenda 2030. [S. l.]: Organização das Nações Unidas, 2017. Disponível em: http://www.agenda2030.org.br/. Acesso em: 10 nov. 2020.

ORGANIZAÇÃO DAS NAÇÕES UNIDAS. Resolução nº 59/113, de 10 de dezembro de 2004. Programa Mundial para a educação em direitos humanos. In: ORGANIZAÇÃO DAS NAÇÕES UNIDAS; ORGANIZAÇÃO DAS NAÇÕES UNIDAS PARA A EDUCAÇÃO, A CIÊNCIA E A CULTURA. Plano de ação: programa mundial para educação em direitos humanos: primeira etapa. Paris: Unesco, 2006. p. 40-43. Disponível em: http://www.dhnet.org.br/dados/textos/edh/br/plano_acao_programa_mundial_edh_pt.pdf. Acesso em: 10 nov. 2020. 
ORGANIZAÇÃO DOS ESTADOS AMERICANOS. Comissão Interamericana de Direitos Humanos. Declaração Universal de Direitos e Deveres do Homem. Bogotá: Conferência Internacional Americana, 1948. Disponível em:

http://www.direitoshumanos.usp.br/index.php/OEA-Organiza\%C3\%A7\%C3\%A3o-dosEstados-Americanos/declaracao-americana-dos-direitos-e-deveres-do-homem.html. Acesso em: 10 nov. 2020.

ORGANIZAÇÃO INTERNACIONAL DO TRABALHO. Declaração Tripartite de Princípios sobre Empresas Multinacionais e a Política Social da Organização Internacional do Trabalho. Genebra: OIT, 2002.

PALMA, Maria Fernanda et al. (org.). Estudos sobre law enforcement, compliance e direito penal. Lisboa: Almedina, 2017.

RODRIGUES, Anabela Miranda. Direito penal econômico: uma política criminal na era compliance. Coimbra: Almedina, 2019.

SAAD-DINIZ, Eduardo. Compliance en la perspectiva de la criminologia económica. Revista de Derecho Penal y Criminologia, Madrid, v. 3, p. 252-267, 2019.

SAAD-DINIZ, Eduardo; SILVEIRA, Renato de Mello. Compliance, direito penal e lei anticorrupção. São Paulo: Saraiva, 2015.

SADEK, Maria Tereza (org.). O judiciário em debate. Rio de Janeiro: Centro Edelstein de Pesquisas Sociais, 2010.

SADEK, Maria Tereza. Judiciário: mudanças e reformas. Estudos Avançados, São Paulo, v. 18, n. 51, p. 79-101, 2004.

SANTOS, Boaventura de Souza. Por uma revolução democrática da justiça. Rio de Janeiro: Civilização Brasileira, 2010.

SARMIENTO, Daniel. El soft law administrativo: un studio de los efectos jurídicos de las normas no vinculantes de la Administración. Madrid: Civitas, 2008.

SILVA SANCHEZ, Jesús Maria. La expansión del derecho penal: aspectos de la politica criminal em las sociedades postindustriales. Madrid: Civitas, 2001.

TARANTINO, Anthony. Introduction. In: TARANTINO, Anthony. The governance, risk and compliance handbook: technology, finance, environmental and international guidance and best practices. Hoboken: John Wiley y Sons, 2008. 